\title{
Effects of Adding Different Proportions of Sunflower Seeds on Fatty Acid Composition of Chicken Tissues
}

\author{
Mawada Mahfoudh ${ }^{1 *}$, Hajer Trabelsi ${ }^{1}$, Khaled Sebei ${ }^{2}$ and Sadok Boukhchina \\ ${ }^{1}$ Biology Department, Lipids Biochemistry Unit, Science Faculty, Tunisia \\ ${ }^{2}$ Biology Department, Higher Institute of Applied Biological Sciences, Tunisia
}

\begin{abstract}
Poultry meat becomes an essential part of our nutrition, our aim is to optimize poultry meat quality to obtain more healthy results. Because of its rich composition of desired fatty acids, we chose sunflower seeds (SS) as chicken's food to search for the best proportion to obtain the best meat composition. A basal diet is given to chickens, with proportions of $25 \%, 50 \%$, and $75 \%$ of sunflower seeds, respectively for each group. The results were very adequate: the more we add SS in chicken's meal, the more its composition is expressed in chickens tissues. So, monounsaturated fatty acids (MUFA) were the major FA, decrease for the favor of polyunsaturated fatty acids (PUFA) in all tissues, linoleic acid become the major FA taking the place of Oleic Acid. Saturated fatty acids (SFA) become, fortunately, lower; it's a target to low the content of SFA, since they have been associated with several human diseases.
\end{abstract}

Keywords: Fatty acids; Chickens; Sunflower seeds; Poultry meat

\section{Introduction}

The quality of meat and animal products has become a major concern for all the poultry sector partners. The lipid content of meat, quality criterion for the consumer, depends on the nutritional characteristics of ingested food, and the quantity and quality of fat added to the diet. In recent years, there has been an increased attention towards the manipulation of the meat lipid amount and composition [1], because of animal sources, such as butter and lard, are characterised by high concentrations of saturated fatty acids. It is well known that a diet rich in saturated fatty acids forms a risk factor for hypercholesterolemia, atherosclerosis and other diseases in humans, in the other side, Many studies have shown the benefits of polyunsaturated fatty acids on human health, especially in relation to heart problems and similarly important diseases [2].

Consequently, poultry meat has become very popular thanks to its nutritional characteristics, Moreover, chicken lipids are characterized by relatively high levels of unsaturated fatty acids, which are considered as a positive and healthy aspect to consumers. So, to obtain a better meat quality, poultry meat is generally manipulated by using a selected food with particular nutritional characteristics. In fact, the ratio of unsaturated to saturated fatty acids in meat should be increased, so to achieve positive health effects $[3,4]$. Thus, the aim of this work is to manipulate chicken food and evaluate the effect of feeding fat sources on the quality and composition of lipids of thighs, breasts and skin of poultry meat.

As feed additive, we used Sunflower seeds in different proportions to see it's impact on muscle FA deposition, in fact, Sunflower (Helianthus annuus L.) is one of the most widely cultivated oilseed in the world and ranks third in importance as a source of vegetable oil [5]. Most studies evaluating effects of seeds FA on poultry meat FA, were experimented by adding the oil of the seed, however, in our experiment, we added the whole seed to the animal (with the bark) and we search for better results. Even though it is an attraction for many consumers, studies on chicken's skin are very low, so, we will try to give details about it. This study provides information on the effects of processing factors on the quality characteristics of chicken's tissues (meat and skin); in economic practice, it is important to determine how to process chicken's meat to preserve its benefits and to reduce harmful components like SFA, this will be established through special feeding to optimize poultry meat quality and to produce new poultry meat ranges, each one specialized and appointed by the food received.

\section{Material and Methods}

\section{Sunflower seeds}

Sunflower seed (SS) should be considered rich in energy, since it has from 3.691 to $5.004 \mathrm{kcal}_{\text {of }}{\mathrm{ME} . \mathrm{kg}^{-1}}$ and from 19.9 to $43.4 \%$ of ether extract $[5,6]$. Varieties with high oil concentration have increased levels of polyunsaturated fatty acids, mainly linoleic [7], and low levels of saturated fatty acids [8].

We chose to give SS to chickens because of its characteristics; sunflower seeds are an excellent source of essential fatty acids, vitamins, minerals and energy. Sunflower kernels actually employed to extract edible oil at commercial levels. Much of their calories come from fatty acids. The seeds are especially rich in poly-unsaturated fatty acids: Linoleic acid (LA), which constitute more than $50 \%$ fatty acids in them. They are also good in mono-unsaturated: Oleic acid (OA) that helps lower LDL or "bad cholesterol" and increases HDL or "goodcholesterol" in the blood. Research studies suggest that Mediterranean diet which is rich in monounsaturated fats help to prevent coronary

*Corresponding author: Mawada Mahfoudh, Biology Department, Lipids Biochemistry Unit, Science Faculty, 2092 El Manar 2, Tunisia, Tel: +21698988320; E-mail: mawada.mahfoudh@yahoo.fr

Received January 22, 2016; Accepted February 12, 2016; Published February 19,2016

Citation: Mahfoudh M, Trabelsi H, Sebei K, Boukhchina S (2016) Effects of Adding Different Proportions of Sunflower Seeds on Fatty Acid Composition of Chicken Tissues. J Food Process Technol 7: 569. doi:10.4172/2157-7110.1000569

Copyright: @ 2016 Mahfoudh M, et al. This is an open-access article distributed under the terms of the Creative Commons Attribution License, which permits unrestricted use, distribution, and reproduction in any medium, provided the original author and source are credited. 
artery disease, and stroke by favoring healthy blood lipid profile [9]. Fatty acid profile of SS is presented in Table 1 [10].

\section{Animal rearing}

One hundred 1-day old broiler chicks were obtained from a commercial hatchery associated to Regional directorate of Agriculture (Nabeul, Tunisia). They are distributed in four parcels in an animal husbandry, They are placed in favorable conditions to their growth (temperature, humidity, aeration, lighting, troughs, foragers, valid nutrition according to age, vaccination, etc.). The Basal Diet (BD) is a nutritionally balanced diet given to chicks just after birth favorising a good nutrition and a healthy growth; it is composed by some proteins, vitamins, trace of minerals and different kinds of seeds. Chicks of each parcel receive a different proportion of diet (Table 2). After 42 days (the breeding period), chickens were slaughtered at a commercial abattoir (slaughterhouse) by cervical dislocation. Muscle is boneless and divided to breasts, thighs and skins separately, meat is minced using a mincing machine and preserved at $-20^{\circ} \mathrm{C}$.

\section{Extraction and analysis}

Total lipids were extracted from chicken muscles using Folch et al. [11] modified by Bligh and Dyer [12], then by Allen and Good [13]. Methyl esters were prepared by transesterification using cold methanolic potassium hydroxyde solution: it's a transmethylation of the triacylglycerols according to the ISO 5509 method (1978). Fatty acid methyl esters (FAME) were analysed by a gas chromatograph.

Gas chromatography of FAME was performed with an agilent

\begin{tabular}{|c|c|}
\hline Fatty acids & Percentage \\
\hline C16:0 & $5.8 \%$ \\
\hline C16:1 & $0.1 \%$ \\
\hline C18:0 & $3.9 \%$ \\
\hline C18:1 & $15.9 \%$ \\
\hline C18:2 & $71.7 \%$ \\
\hline C18:3 & $0.6 \%$ \\
\hline C18:3 & $0.1 \%$ \\
\hline C20:0 $20: 1$ & $0.3 \%$ \\
\hline C22:0 & $0.2 \%$ \\
\hline C24:0 & $0.7 \%$ \\
\hline
\end{tabular}

Table 1: Sunflower seeds fatty acids composition.

\begin{tabular}{|c|c|c|c|c|} 
& Parcel 1 & Parcel2 & Parcel3 & Parcel4 \\
\hline SS & $25 \%$ & $50 \%$ & $75 \%$ & $0 \%$ \\
\hline BD & $75 \%$ & $50 \%$ & $25 \%$ & $100 \%$ \\
\hline
\end{tabular}

SS: Sunflower Seeds; $25 \%$ SS: Chicks fed $25 \%$ SS of the total diet; BD: Basa Diet ; $50 \%$ SS: Chicks fed $50 \%$ SS of the total diet; $75 \%$ SS: Chicks fed $75 \%$ of the total diet

Table 2: The ration given to each parcel.
$6890 \mathrm{~N}$ gas chromatography equipped with a flame ionization detector (FID). The operating conditions for the gas chromatograph were as follows; we began by a temprature of $75^{\circ} \mathrm{C}$, increasing by $5^{\circ} \mathrm{C} / \mathrm{min}$ to $148^{\circ} \mathrm{C}$, from 148 to $158^{\circ} \mathrm{C}$, the temperature was increased by $2.5^{\circ} \mathrm{C} /$ min, from 158 to $225^{\circ} \mathrm{C}$ per min, the temperature was increased at the rate of $5^{\circ} \mathrm{C} / \mathrm{min}$. The temperature of the injector and the detector remained stable at $280^{\circ} \mathrm{C}$. The column head pressure of the conductor gas (helium) was $1.3 \mathrm{~g} / \mathrm{cm}^{2}$

\section{Statistical analysis}

The experimental data were analyzed using the analysis of variance (ANOVA) and the Statistical Analysis System (XLSTAT 2013) (Addinsoft USA). Differences at $\mathrm{p} \leq 0.05$ were considered statistically significant by Duncan's new multiple range test. All values were expressed as means \pm standard deviation of at least triplicate repetitions. Each value is a mean \pm standard deviation (SD) of a triplicate analysis performed on different samples Means with different letters were significantly different with $\mathrm{p} \leq 0.05$.

\section{Results}

\section{Effects on breast's fatty acids}

The effects of experimental diets (SS), in its different proportions, on breast FA profile is in Table 3; Ten fatty acids(FA) were found in the analyse of FAME. Most of values Were considered statically significant by Duncan's new multiple range test. The major FA in standard breast is oleic acid, same result for chicks fed $25 \%$ SS and $50 \%$ SS, then it's reversed at $75 \%$ SS, major FA become linoleic acid, the difference is significant $(\mathrm{p} \leq 0.05)$. Palmitic acid exist too with a sufficient percentage, but, it decrease significantly ( $\mathrm{p} \leq 0.05$ ) with the consumption of SS, like all other saturated fatty acids (Myristic, stearic, arachidic, béhénic).

Breast's TFA (total fatty acids) evolution are shown in Figure 1. It shows that SFA of breast decrease with consumption of sunflower seeds whatever the proportion, their most decrease is at $75 \%$ SS and this proportion represent the top of PUFA $(40.730 \%)$ and the best propotion of UFA (77.744\%) values. Concerning MUFA (C16:1, C18:1, C22:1), they are concentrated in the breast of standard chickens with the highest value, same for SFA, with consumption of SS, they decrease for the favor of PUFA which are in remarkable evolution: from $24.07 \%$ to $40.73 \%$, the highest level of UFA is in $75 \%$ SS chicks group. The polyunsaturated to saturated fatty acid ratio $(\mathrm{P} / \mathrm{S})$ is around $1.1 \%$ but it has a peak in chick's breast of $75 \%$ SS it reaches $1.828 \%$.

\section{Effects on thigh's FA}

Table 4 shows the effects of Sunflower Seeds on FA profile of Thigh. In first steps of minimum added diet, (standard and 25\% SS) thigh's predominant FA is oleic acid; the more chicks consume SS the more oleic acid decrease, the more linoleic acid increase, so, in $50 \%$ and $75 \%$ proportions, the predominant FA becomes linoleic acid (C18:2n-6).

\begin{tabular}{|c|c|c|c|c|c|c|c|c|c|c|c|c|c|c|c|}
\hline & C14:0 & C16:0 & C16:1 & C18:0 & C18:1 (n-9) & C18:2 (n-6) & C18:3 (n-3) & C20:0 & C22:0 & C22:1 & SFA & MUFA & PUFA & UFA & P/S \\
\hline Standard(BD) & $0.460^{c}$ & $21.880^{d}$ & $4.860^{d}$ & $6.385^{b}$ & $39.940^{c}$ & $24.070^{a}$ & $0.000^{\mathrm{a}}$ & $1.845^{\mathrm{c}}$ & $0.180^{\mathrm{b}}$ & $0.380^{\mathrm{b}}$ & 30.750 & 45.180 & 24.070 & 69.250 & 1.124 \\
\hline $25 \%$ SS & $0.440^{\mathrm{bc}}$ & $17.785^{b}$ & $2.370^{\mathrm{b}}$ & $7.140^{d}$ & $38.180^{b c}$ & $30.925^{b}$ & $0.570^{d}$ & $2.000^{d}$ & $0.150^{b}$ & $0.440^{c}$ & 27.515 & 40.989 & 31.495 & 72.483 & 1.144 \\
\hline $50 \%$ SS & $0.410^{b}$ & $19.380^{c}$ & $4.060^{c}$ & $7.140^{d}$ & $36.935^{a}$ & $31.860^{b}$ & $0.190^{\mathrm{b}}$ & $1.490^{\mathrm{b}}$ & $0.075^{\mathrm{a}}$ & $0.320^{\mathrm{a}}$ & 28.495 & 41.313 & 32.050 & 73.363 & 1.124 \\
\hline $75 \%$ SS & $0.235^{\mathrm{a}}$ & $14.220^{\mathrm{a}}$ & $1.575^{\mathrm{a}}$ & $6.575^{c}$ & $35.075^{a}$ & $40.365^{c}$ & $0.365^{c}$ & $1.045^{\mathrm{a}}$ & $0.200^{\mathrm{b}}$ & $0.365^{b}$ & 22.275 & 37.014 & 40.730 & 77.744 & 1.828 \\
\hline
\end{tabular}

Values are mean $\pm \mathrm{SD}$. Values that are followed by different letters within each row are significantly different $(p \leq 0.05)$

SFA: Saturated Fatty Acids; MUFA: Monounsaturated Fatty Acids; PUFA: Polyunsaturated Fatty Acids; UFA: Unsaturated Fatty Acids; P/S: Polyunsaturated to Saturated Fatty Acids Ratio; STD: Standard Chicks Fed Basal Diet; $25 \%$ SS: Chicks fed $25 \%$ Sunflower Seeds of the total diet; $50 \%$ SS: Chicks fed $50 \%$ Sunflower Seeds of their total diet; $75 \%$ SS: Chicks fed $75 \%$ Sunflower Seeds of their total diet.

Table 3. Fatty acids profile of chicken's breast. 
The effect of treatments on concentration of FA (C14:0, C16:0, C16:1, C18:0, C18:1, C18:2) was noticeable ( $\mathrm{p} \leq 0.05)$. TFA evolution is shown in Figure 2. Thigh's SFA decrease with the consumption of SS; it begins by $32.695 \%$ for standard ration and decreases proportionally with the increase of SS propotion, it becomes $21.715 \%$ for $75 \%$ SS. The same experience showed a significant effect on MUFA in thigh, it decreases proportionally with consumption of SS. While, PUFA grow increasingly with consumption of Sunflower seeds and reaches $46.685 \%$ at $75 \%$ of SS of total alimentation, so, UFA develop too with the uptake of Sunflower seeds.

\section{Effects on skin's FA}

Skin tissue is also analysed. It was affected by Sunflower seeds nourishment. The results has been shown in Table 5. Even for Skin, the same results are found; oleic acid, is the major FA for standard group and it stays the same in 25\% SS group, then it's reversed in 50\% SS and $75 \%$ SS ration to the linoleic acid. SFA and MUFA decrease with the SS uptake to the favor of PUFA in fat tissue too (Figure 3).

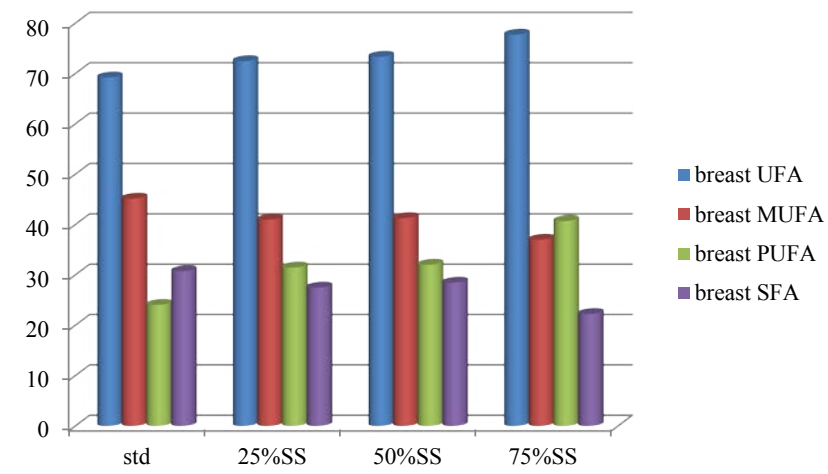

SFA: Saturated Fatty Acids; MUFA: Monounsaturated Fatty Acids; PUFA Polyunsaturated Fatty Acids; UFA: Unsaturated Fatty Acids; STD: Standard Chicks Fed Basal Diet; $25 \%$ SS: Chicks fed 25\% Sunflower Seeds of the total diet; $50 \%$ SS: Chicks fed $50 \%$ Sunflower Seeds of their total diet; $75 \%$ SS: Chicks fed $75 \%$ Sunflower Seeds of their total diet.

Figure 1: Breast TFA evolution in terms of food percentage.

\section{Discussion}

The breast's major FA is oleic acid at $25 \%$ and $50 \%$ SS. Our major FA is reversed at $75 \%$ SS, it becomes linoleic acid with a very important percentage (40.365\%). Crespo and Esteve Garcia [14] proved that Birds fed sunflower oil showed higher values of linoleic acid (c18:2 n-6) than those fed tallow, olive, or linseed oil. Oleic acid was the second FA (since $75 \%$ SS) like in SSFA (sunflower seeds FattyAcids) (Table 2) and in chicken's meat FA: Table 2, showing SSFA composition, demonstrate that this composition is reflected on FA profile of chicken's meat. The major FA (linoleic acid(LA)) of SS (71\%) influenced LA in chicken tissue, it becomes $40 \%$. However it beomes the second FA (at 75\% SS), oleic acid have anyway an important value staying relatively high and beneficial.

MUFA and SFA are concentrated in the breast and thigh of standard chicken with high percentages, they decrease for the favor of PUFA. Similar trends are reported by Grau et al. [15] who determined

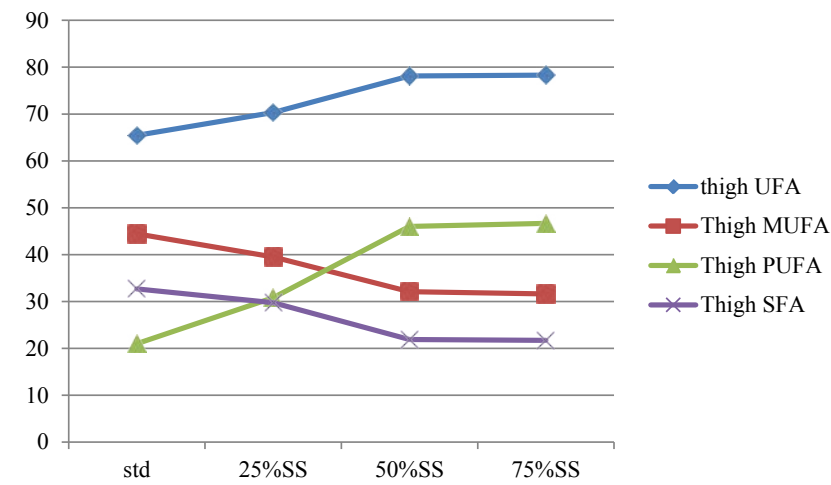

SFA: Saturated Fatty Acids; MUFA: Monounsaturated Fatty Acids; PUFA Polyunsaturated Fatty Acids; UFA: Unsaturated Fatty Acids; STD: Standard Chicks Fed Basal Diet; $25 \%$ SS: Chicks fed 25\% Sunflower Seeds of the total diet; $50 \%$ SS: Chicks fed $50 \%$ Sunflower Seeds of their total diet; $75 \%$ SS Chicks fed $75 \%$ Sunflower Seeds of their total diet.

Figure 2: Thigh TFA evolution relative to SS percentage.

\begin{tabular}{|c|c|c|c|c|c|c|c|c|c|c|c|c|c|c|c|}
\hline & C14:0 & C16:0 & C16:1 & C18:0 & C18:1 (n-9) & C18:2 (n-6) & C18:3 (n-3) & C20:0 & C22:0 & C22:1 & SFA & MUFA & PUFA & UFA & P/S \\
\hline Standard(BD) & $0.570^{c}$ & $23.645^{c}$ & $4.995^{c}$ & $6.620^{\mathrm{b}}$ & $39.125^{c}$ & $20.850^{a}$ & $0.155^{\mathrm{a}}$ & $1.725^{\mathrm{a}}$ & $0.135^{\mathrm{a}}$ & $0.320^{\mathrm{a}}$ & 32.695 & 44.440 & 21.005 & 65.445 & 0.642 \\
\hline $25 \%$ SS & $0.430^{\mathrm{b}}$ & $20.025^{b}$ & $3.130^{\mathrm{a}}$ & $7.340^{c}$ & $36.080^{b}$ & $30.625^{b}$ & $0.190^{\mathrm{a}}$ & $1.815^{\mathrm{a}}$ & $0.125^{\mathrm{a}}$ & $0.295^{\mathrm{a}}$ & 29.735 & 39.505 & 30.815 & 70.320 & 1.036 \\
\hline $50 \%$ SS & $0.285^{\mathrm{a}}$ & $13.770^{\mathrm{a}}$ & $1.900^{\mathrm{a}}$ & $6.325^{\mathrm{a}}$ & $29.860^{a}$ & $45.880^{c}$ & $0.140^{\mathrm{a}}$ & $1.335^{\mathrm{a}}$ & $0.165^{\mathrm{a}}$ & $0.335^{\mathrm{a}}$ & 21.880 & 32.095 & 46.020 & 78.115 & 2.100 \\
\hline $75 \%$ SS & $0.325^{a}$ & $13.860^{\mathrm{a}}$ & $2.060^{\mathrm{a}}$ & $6.470^{\mathrm{ab}}$ & $29.230^{\mathrm{a}}$ & $46.505^{c}$ & $0.180^{\mathrm{a}}$ & $0.920^{\mathrm{a}}$ & $0.140^{\mathrm{a}}$ & $0.325^{\mathrm{a}}$ & 21.715 & 31.615 & 46.685 & 78.300 & 2.149 \\
\hline
\end{tabular}

Values are mean $\pm S D$. Values that are followed by different letters within each row are significantly different $(p \leq 0.05)$

SFA: Saturated Fatty Acids; MUFA: Monounsaturated Fatty Acids; PUFA: Polyunsaturated Fatty Acids; UFA: Unsaturated Fatty Acids; P/S: Polyunsaturated to Saturated Fatty Acids Ratio; STD: Standard Chicks Fed Basal Diet; $25 \%$ SS: Chicks fed 25\% Sunflower Seeds of the total diet; $50 \%$ SS: Chicks fed $50 \%$ Sunflower Seeds of their total diet; $75 \%$ SS: Chicks fed $75 \%$ Sunflower Seeds of their total diet.

Table 4: Fatty acids profile of thigh meat.

\begin{tabular}{|c|c|c|c|c|c|c|c|c|c|c|c|c|c|c|c|}
\hline & C14:0 & C16:0 & C16:1 & C18:0 & C18:1 (n-9) & C18:2 (n-6) & C18:3 (n-3) & C20:0 & C22:0 & $\mathrm{C} 22: 1$ & SFA & MUFA & PUFA & UFA & P/S \\
\hline $\begin{array}{l}\text { Standard } \\
\text { (BD) }\end{array}$ & $0.46 c$ & $23.060^{d}$ & $5.110^{d}$ & $7.360^{\circ}$ & $39.730^{c}$ & $21715^{\mathrm{a}}$ & $0 \cap 0 \Omega^{\text {a }}$ & $2.295^{c}$ & $0.120^{c}$ & $0.150^{\mathrm{a}}$ & 33.295 & 44.990 & 21.715 & 66.705 & 652 \\
\hline $25 \%$ SS & $0.455^{b}$ & $20.475^{c}$ & $2.630^{\circ}$ & $8.250^{d}$ & $35.165^{b}$ & $31.590^{b}$ & $0.120^{\mathrm{b}}$ & $1.210^{\mathrm{b}}$ & $0.000^{\mathrm{a}}$ & $0.110^{\mathrm{a}}$ & 30.390 & 37.905 & 31.710 & 68.615 & 1.043 \\
\hline $50 \%$ SS & $0.310^{\mathrm{a}}$ & $15.365^{b}$ & $1.990^{\mathrm{a}}$ & $7.140^{\mathrm{b}}$ & $31.290^{\mathrm{a}}$ & $40.105^{c}$ & $0.180^{c}$ & $3.090^{d}$ & $0.100^{\mathrm{bc}}$ & $0.430^{\mathrm{b}}$ & 26.005 & 33.710 & 40.285 & 73.995 & 1.549 \\
\hline $75 \%$ SS & $0.365^{\mathrm{a}}$ & $14.720^{a}$ & $2.230^{\mathrm{b}}$ & $5.675^{\mathrm{a}}$ & $32.330^{\mathrm{a}}$ & $43.510^{d}$ & $0.325^{d}$ & $0.645 a$ & $0.070^{\mathrm{b}}$ & $0.130^{\mathrm{a}}$ & 21.475 & 33.710 & 43.835 & 78.525 & 2.041 \\
\hline
\end{tabular}

Values are mean $\pm S D$. Values that are followed by different letters within each row are significantly different $(p \leq 0.05)$

SFA: Saturated Fatty Acids; MUFA: Monounsaturated Fatty Acids; PUFA: Polyunsaturated Fatty Acids; UFA: Unsaturated Fatty Acids; P/S: Polyunsaturated to Saturated Fatty Acids Ratio; STD: Standard Chicks Fed Basal Diet; $25 \%$ SS: Chicks fed $25 \%$ Sunflower Seeds of the total diet; $50 \%$ SS: Chicks fed $50 \%$ Sunflower Seeds of their total diet; $75 \%$ SS: Chicks fed $75 \%$ Sunflower Seeds of their total diet.

Table 5: Fatty acids profile of skin. 


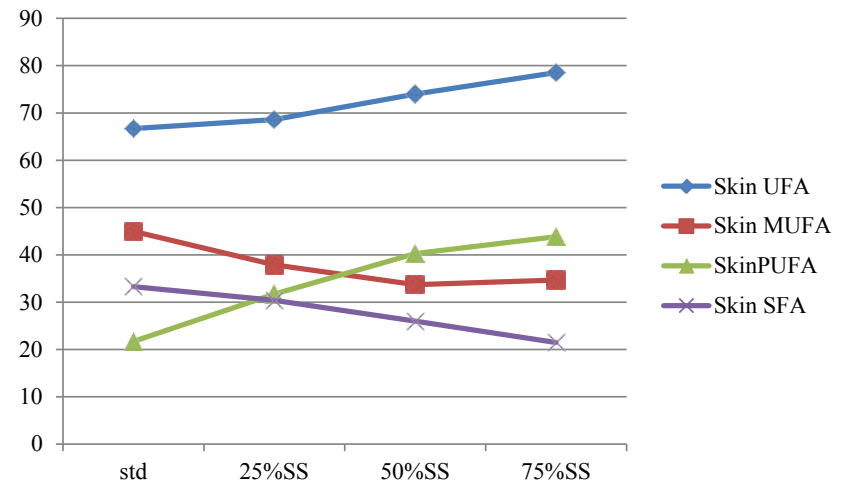

SFA: Saturated Fatty Acids; MUFA: Monounsaturated Fatty Acids; PUFA Polyunsaturated Fatty Acids; UFA: Unsaturated Fatty Acids; STD: Standard Chicks Fed Basal Diet; $25 \%$ SS: Chicks fed $25 \%$ Sunflower Seeds of the total diet; $50 \%$ SS: Chicks fed $50 \%$ Sunflower Seeds of their total diet; $75 \%$ SS: Chicks fed $75 \%$ Sunflower Seeds of their total diet.

Figure 3: Skin TFA evolution relative to food level.

that raw meat from chickens fed with beef tallow had $34.41 \%$ SFA, 47.29\% MUFA, and $18.34 \%$ PUFA, whereas those fed with sunflower oil showed 22.62\% SFA, 34.96\% MUFA, and 42.47\% PUFA [16].

As regards to the skin, like the thigh and breast, skin's linoleic acid grow up proportionally with the consumption of sunflower seeds. Viveros et al. [17] also, showed significant differences in the fatty acid concentrations of abdominal fat among dietary fat sources. The contents of the major fatty acids, palmitic acid (C16:0), stearic acid (C18:0), oleic acid (C18:1n-9), and linoleic acid (C18:2n-6) in abdominal fat reflected the fatty acid profile of the dietary fat. The C18:2n-6 content was significantly greater in Conventional SS diets. The PUFA/MUFA and UFA/SFA ratios were significantly increased (up to $44 \%$ ). In our experiment, diet's FA are well expressed in fat tissue, even like muscle tissue. Maria et al. [18] showed that it should be stressed that dietary fatty acid composition is best represented by fat tissue rather than muscle tissue. The results of Ortiz et al. [19], showed too a more efficient modification of adipose than intramuscular fat profile, which was probably due to the physiological lipid storage function of adipose tissue.

To synthesize, SFA and MUFA decreases for the favor of PUFA in all tissues (Figures 1-3). Consequently, P/S ratio increase from $0.642 \%$ for standard group to $2.149 \%$ for $75 \%$ SS group. Likewise Ortiz et al. [19] found too that when we feed chickens with a source of fat in C18:1n-9 (HOASS(high oleic acid sunflower seeds) or its oil), or C18:2n-6(CSS(conventional sunflower seeds) or its oil), the proportion of MUFA and PUFA, respectively, increased in abdominal fat as well as in breast and thigh muscles. The proportionality is detected too in the experience of Lopez-Ferrer et al. [20] who used different percentages of flaxseed oil in diets for chicken and obtained different values of Linolenic acid in chicken meat. Increasing the flaxseed oil decreased the SFA and MUFA and increased the PUFA [13]. Breast, thigh and Skin, are affected by food quantity and quality, indeed, the amount added to the diet has changed the quantity (in\%) of meat and fat tissue FA, and the quality of FA of the seeds (FASS) is reproduced on the quality of meat FA, and fat tissues.

Comparing breast's and thigh's and skin's FA, we note that thigh and skin are more sensitive to dietry FA than breast; their FA composition is changed and their major FA becomes Linoleic Acid from $50 \%$ SS ration (Breast at $75 \%$ SS). In $25 \%$ SS ration, results are not well expressed in all tissues, this could be explained by the lower level of fat added, as it has been stated, the dietry fatty acids incorporated into the muscular tissues will be relatively more diluted by de novo synthesized fatty acids at low fat intakes than at high fat intakes, Ortiz et al. [19] and Hardinka et al. [21] Confirm this. It appears that the increased PUFA with proportional decrease of MUFA and SFA are related phenomena, in fact, the concentration of PUFA is resulted from direct deposition of diet fat [22], it is assumed that MUFA and SFA give way to PUFA and degrade in liver, in this direction, Cortinas et al. [23] Showed that with increase in concentration of PUFA in diet, concentration of MUFA decreases in tissue, these results were also obtained by schreiner et al. [24], and Dobrzaneki et al. [25].

Chicks fed sunflower oil showed higher values of linoleic acid (c18:2 n-6), linoleic acid replaced myristic, palmitic, stearic and oleic acids in all tissues [14]. This suggest the same hypothesis that these FA are leaving tissues letting place to other FA derived from diet (essentially PUFA by direct deposition). Where as, Lopez-Ferrer et al. [26] reported that the concentration of SFA and MUFA in tissue have completely dependence on contents of diet. They maintained that this may be dependent on relation between conversion in liver, deposition on tissue and turnover from carbohydrates. Normally in poultry, de novo lipogenesis occurs in the liver from dietary carbohydrates, reactions catalyzed by both: glucose-6-phosphate dehydrogenase and malic enzyme that provide the reduced equivalents required for de novo synthesis. Subsequently, triglycerides are hydrolyzed into glycerol and fatty acids and transported to adipose tissue in chylomicrons and very low density lipoprotein [27] deposited in the fatty organ or oxidized to obtain energy [28-30]. In fact, Doreau and Chilliard [31], show that In birds, the effects of adding dietary fats on adipose tissue metabolism are secondary to changes in lipid metabolism in the liver (the main site of FA synthesis in these species). The reduction of dietary carbohydrates when fat is supplied in the diet decreases the de novo synthesis of FA [32] and VLDL secretion by the liver. The proportion of dietary FA in circulating lipids then increases, so that body fat mainly depends on the direct uptake of exogenous FA. Due to the reduction of de novo FA synthesis, body fat deposition mainly depends on the direct uptake of preformed FA. For this reason, FA composition of body lipids is highly correlated to the nature of FA intake. For example, the proportion of linolenic acid in body fat of chickens fed with linseed oil can reach 34 $\mathrm{g} / 100 \mathrm{~g}$ instead of $1 \mathrm{~g} / 100 \mathrm{~g}$ with classical diets [33]. In broilers, lipid classes are unevenly distributed in different tissues; triacylglycerols, the most abundant, and the most affected by food, polar lipids were little affected, triacylglycerols carry with them, so, the dietry lipids to different muscle tissues $[19,20]$. Since the recommended low value of $n-6 / n-3$ ratio, and knowing that chicken's meat is not a source of n- 3 FA, the proportion of $75 \%$ which has incured a remarkable transformation and a great increase in n-6 FA, could be discouraged because of the high level of $n-6 / n-3$ ratio (high value of $n-6$ ) which can be noxious on the oxidative situation; But we could contradict this hypothesis as our added diet is an excellent source of vitamin E [34], the body's primary fat-soluble antioxidant, it plays an important role in the prevention of cardiovascular disease. It is one of the main antioxidants found in cholesterol particles and helps prevent free radicals from oxidizing cholesterol. Vitamin E has significant anti-inflammatory effects that result in the reduction of symptoms in asthma, osteoarthritis, and rheumatoid arthritis, conditions where free radicals and inflammation play a big role. Vitamin $\mathrm{E}$ has also been shown to reduce the risk of colon cancer, help decrease the severity and frequency of hot flashes in women going through menopause, and help reduce the development 
of diabetic complications [34]. All these benefits of SS are reproduced in chickens and will help to defend against drawbacks of n-6/n-3 (if any). The best proportion in our work could be $50 \%$ SS since both FA, Linoleic acid and Oleic Acid are very narrow range giving the desired nutritional balance. A remarquable difference between n-3 and n-6 FA in our experiment, this distribution is not aleatory, the highest values of $\mathrm{n}-6$ fatty acids were found in thighs and breasts of birds fed sunflower seeds, possibly due to the competition for $\Delta-5$ and $\Delta-6$ desaturase between n-3 and n- 6 fatty acids in these tissues. For the same reason, the lowest values of $n-3$ derivatives were found in muscles of birds fed sunflower. These results are in accordance with Crespo and EsteveGarcia [14]. Differences in tissue fatty acid profiles could be attributed to different roles of fatty acids in these tissues or to their different contents of phospholipids. PUFA are preferentially incorporated into phospholipids [35] and phospholipids are in higher proportion in muscle fat than in adipose tissue fat [36], which could explain different compositions of fat in different tissues.

So, As already reported in literature [37-42] the fat sources used as integration for diets can effectively affect the fatty acid composition of monogastric's lipid tissues [16]. Marion and Woodroof [43] too, found that the fatty acid composition in broiler tissues was easily influenced by dietry lipids.

\section{Conclusion}

Adding the whole seed to chicken's diet proved that it is easier and gives significant results. The addition of SS in the poultry diet cause an increase in n-6 FA of their meat. L.A is the major FA, but oleic acid is the second one and its values stay relatively high and beneficial (about $30 \%$ ). The wealth of meat by UFA, SFA, (n-6) FA, P/S ratio are proportional to consumption of sunflower seeds by chickens. Thigh is more sensitive to dietry FA than breast, it acquires the effects of SS from $50 \%$ SS (Breast at 75\% SS);the difference is related to richness of each muscle by phospholipids and triacylglycerols essentially, since total fatty acid intake is the same (the same chicken). FA composition of body lipids is highly correlated to the nature of FA intake, and the concentration of PUFA is resulted from direct deposition of diet fat. Poultry meat, a low-fat meat compared with red meat, and rich by PUFA (in our case), is usually recommended by dieticians, but, Some researchers find the large amount of n-6 discouraged, although, in our experience we can say that it is beneficial due to its origin from SS, source of vitamin E, a luxury antioxidant. So, it is concluded that the seeds of conventional varieties of sunflower might be used in poultry feeding in order to increase PUFA contents in both abdominal adipose tissue and intramuscular fat. Adding proportions in ascending order of SS to the parcels, proves that a proportionality is established in the quality and quantity of FA; This will have a great importance in poultry economy by producing types of chicken's meat according to all tastes and needs of consumers; So, we can manipulate chicken meat as we want by adding the food that suits with our needs, it will be reproduced in the meat; we could process by the same technical way to produce: n-3 chickens, n-6 chickens (our study), O.A chickens, SFA chickens, etc. to meet urban demand.

\section{References}

1. Wood JD, Richardson RI, Nute GR, Fisher AV, Campo MM, et al. (2004) Effects of fatty acids on meat quality: a review. Meat Sci 66: 21-32.

2. Leskanich CO, Noble RC (1997) Manipulation of the n-3 polyunsaturated fatty acid composition of avian eggs and meat. World's Poultry Science Journal 53: 155-183

3. Reddy BS (1995) Nutritional factors and colon cancer. Crit Rev Food Sci Nutr 35: $175-190$.
4. Søyland E, Drevon CA (1993) The effect of very long-chain n-3 fatty acids on immune-related skin diseases. Eur J Clin Nutr 47: 381-388.

5. Ortiz LT, Alzueta C, Rebolé A, Rodriguez ML, Arija I, et al. (2006) Effect of dietry high oleic acid and conventional sunflower seeds and their refined oils on fatty acid composition of aadipose tissue and meat in broiler chickens. Journal of animal and feed sciences. 15: 83-95.

6. Cheva IB, Tangtaweewipat S (1990) Effect of different levels of sunflower seed in broiler rations. Poultry Science 70: 2284-2294.

7. Senkoylu N, Dale N (1999) Sunflower meal in poultry diets: a review. World's Poultry Science Journal. 55: 153-174.

8. Pelegrini B, Girassol (1989) Uma planta solar que da América conquistou o mundo. São Paulo, Ícone.

9. Umesh R (2015) Sunflower seeds nutrition facts.

10. Esoteric Oils CC, Sallamander Concepts (2010) The world of pure essential oils.

11. Folch J, Lees M, Sloan SGH (1957) A simple method for the isolation and purification of total lipids from animal tissues. Journal of Biological Chemistry 226: 497-509.

12. Bligh EG, Dyer WJ (1959) A rapid method for total lipid extraction and purification. Can J Biochem Physiol 37: 911-917.

13. Allen CF, Good P (1971) Acyl lipids in photosynthetic systems. Methods enzymol 13: 523-547.

14. Crespo N, Esteve-Garcia E (2001) Dietary fatty acid profile modifies abdominal fat deposition in broiler chickens. Poult Sci 80: 71-78.

15. Grau A, Codony R, Grimpa S, Baucells MD, Guardiola F, et al. (2001) Cholesterol oxidation in frozen dark chicken meat: influence of dietary fat source, and $\hat{I} \pm$ tocopherol and ascorbic acid supplementation. Meat Sci 57: 197-208.

16. Matteo B, Maria FC, Maria TR, Giovanni L (2006) Effect of feeding fat sources on the quality and composition of lipids of precooked ready-to-eat fried chicken patties. Food Chemistry 10: 1327-1337.

17. Viveros A, Ortiz LT, Rodríguez ML, Rebolé A, Alzueta C, et al. (2009) Interaction of dietary high-oleic-acid sunflower hulls and different fat sources in broiler chickens. Poult Sci 88: 141-151.

18. Maria CM, Roseli GP, Carmino H, Nilson ES, Makoto M, et al. (2003) Influence of diets enriched with different vegetable oils on the fatty acid profiles of snail Helix aspersa maxima. Food Chemistry 82: 553-558.

19. Rodríguez ML, Ortiz LT, Alzueta C, Rebolé A, Treviño J, et al. (2005) Nutritive value of high-oleic acid sunflower seed for broiler chickens. Poult Sci 84: 395-402.

20. Sanz M, Carmona JM, Lopez-Bote CJ (2002) Quantitative effect of dietry fatty acids on fatty acid composition and fat firmness in broilers. Arch Geflugelk 66 : 211-215.

21. Hardinka C, Zollitsch W, Knaus W, Lettner F (1996) Effects of dietary fatty acid pattern on melting point and composition of adipose tissues and intramuscular fat of broiler carcasses. Poult Sci 75: 208-215.

22. Ali AS, Hossein I, Mohammad KT, Mohammad C (2012) Fatty Acids Profiles in Meat of Broiler Chicks Fed Diet Containing Corn Oil Switched to Fish Oil at Different Weeks of Age. World Applied Sciences Journal 18: 159-165.

23. Cortinas L, Villaverde C, Galobart J, Baucells MD, Codony R, et al. (2004) Fatty acid content in chicken thigh and breast as affected by dietary polyunsaturation level. Poult Sci 83: 1155-1164.

24. Schreiner M, Hulan HW, Razzazi-Fazeli E, Bohm J, Moreira R, et al. (2005) Effect of different source of dietary omega-3 fatty acid on general performance and fatty acid profiles of thigh, breast, liver and portal blood of broilers. J Sci Food Agric 85: 216-226.

25. Dobrzañski Z, Jamroz D, Bykowski P, Trziszka T (2002) Effect of fish oil on broiler performance and meat quality, Electronic. Journal of Polish Agriculture Universities 1: 43-51.

26. López-Ferrer S, Baucells MD, Barroeta AC, Galobart J, Grashorn MA, et al. (2001) n-3 enrichment of chicken meat. Use of precursors of long-chain polyunsaturated fatty acids: linseed oil. Poult Sci 80 : 753-761.

27. Mourot J, Hermier D (2001) Lipids in monogastric animal meat. Reprod Nutr Dev 41: 109-118.

28. Ferrini G, Manzanilla EG, Menoyo D, Esteve GE, Baucells MD, et al. (2010) 
Citation: Mahfoudh M, Trabelsi H, Sebei K, Boukhchina S (2016) Effects of Adding Different Proportions of Sunflower Seeds on Fatty Acid Composition of Chicken Tissues. J Food Process Technol 7: 569. doi:10.4172/2157-7110.1000569

Effects of dietary n-3 fatty acids in fat metabolism and thyroid hormone levels when compared to dietary saturated fatty acids in chickens. Livest Sci 131 : 287-291.

29. Žlender B, Antonija H, Vekoslava S, Polak T (2000) Fatty acid composition of poultry meat from free range rearing. Poljopriverda 6: 53-56.

30. Alvarez MJ, Díez A, López-Bote C, Gallego M, Bautista JM, et al. (2000) Short-term modulation of lipogenesis by macronutrients in rainbow trout (Oncorhynchus mykiss) hepatocytes. Br J Nutr 84: 619-628.

31. Doreau M, Chilliard $Y$ (1997) Digestion and metabolism of dietary fat in farm animals. Br J Nutr 78 Suppl 1: 15-35.

32. Hillard BL, Lundin P, Clarke SD (1980) Essentiality of dietary carbohydrate for maintenance of liver lipogenesis in the chick. J Nutr 110: 1533-1542.

33. Edwards HM, Hart P (1971) Carcass composition of chickens fed carbohydratefree diets containing various lipid energy sources. J Nutr 101: 989-996.

34. The George Mateljan Foundation (2015) The world's healthiest foods.

35. Whitehead CC, Armstrong J, Herron KM (1990) The growth to maturity of lean and fat lines of broiler chickens given diets of different protein content: body composition, plasma lipoprotein concentration and initial egg production. Anim Prod 50: 183-190.
36. Enser M, Wiseman J (1984) The chemistry, biochemistry and nutritional importance of animal fats. Fats in Animal Nutriton, London, UK.

37. Daghir NJ, Raz MA, Uwayjan M (1980) Studies the utilization of full fat sunflower seed in broiler rations. Poultry Science 59: 2273-2278.

38. Bou R, Guardiola F, Grau A, Grimpa S, Manich A, et al. (2001) Influence of dietary fat source, alpha-tocopherol, and ascorbic acid supplementation on sensory quality of dark chicken meat. Poult Sci 80: 800-807.

39. Gray JI, Crackel RL, Ledward DA, Johnston DE (1992) Oxidative flavour changes in meats: their origin and prevention. The chemistry of muscle-based foods. The Royal Society of Chemistry, Cambridge, UK.

40. Lin CF, Gray JI, Asghar A, Buckley DJ, Booren AM, et al. (1989) Effects of dietary oils and a-tocopherol supplementation on lipid composition and stability of broiler meat. J Food Sci 54: 1457-1460.

41. Gallardo MA, Pérez DD, Leighton FM (2012) Modification of fatty acid composition in broiler chickens fed canola oil. Biol Res 45: 149-161.

42. O'Neill LM, Galvin K, Morrissey PA, Buckley DJ (1998) Comparison of effects of dietary olive oil, tallow and vitamin $\mathrm{E}$ on the quality of broiler meat and meat products. Br Poult Sci 39: 365-371.

43. Marion JE, Woodroof JG (1963) The fatty acid composition of breast, thigh and skin tissues of chicken broilers as influenced by dietary fats. Poultry Sci 42: $1202-1207$. 